\title{
Adverse Outcomes After Hospitalization and Delirium in Persons With Alzheimer Disease
}

\section{Citation}

Fong, Tamara G., Richard N. Jones, Edward R. Marcantonio, Douglas Tommet, Alden L. Gross, Daniel Habtemariam, Eva Schmitt, Liang Yap, and Sharon K. Inouye. 2012. Adverse Outcomes After Hospitalization and Delirium in Persons With Alzheimer Disease. Ann Intern Med 156, no. 12: 848. doi:10.7326/0003-4819-156-12-201206190-00005.

\section{Published Version}

doi:10.7326/0003-4819-156-12-201206190-00005

\section{Permanent link}

http://nrs.harvard.edu/urn-3:HUL.InstRepos:33751056

\section{Terms of Use}

This article was downloaded from Harvard University's DASH repository, and is made available under the terms and conditions applicable to Other Posted Material, as set forth at http:// nrs.harvard.edu/urn-3:HUL.InstRepos:dash.current.terms-of-use\#LAA

\section{Share Your Story}

The Harvard community has made this article openly available.

Please share how this access benefits you. Submit a story.

\section{Accessibility}




\title{
Adverse Outcomes After Hospitalization and Delirium in Persons With Alzheimer Disease
}

\author{
Tamara G. Fong, MD, PhD, Richard N. Jones, ScD, Edward R. Marcantonio, MD, SM, \\ Douglas Tommet, MS, Alden L. Gross, PhD, MHS, Daniel Habtemariam, BA, Eva Schmitt, \\ PhD, Liang Yap, PhD, and Sharon K. Inouye, MD, MPH \\ Aging Brain Center, Institute for Aging Research, Hebrew SeniorLife; Beth Israel Deaconess \\ Medical Center, Harvard Medical School; and Massachusetts General Hospital, Harvard Medical \\ School, Boston, Massachusetts
}

\section{Abstract \\ Background-Hospitalization, frequently complicated by delirium, can be a life-changing event for patients with Alzheimer disease (AD). \\ Objective-To determine risks for institutionalization, cognitive decline, or death associated with hospitalization and delirium in patients with AD.}

Design-Prospective cohort enrolled between 1991 and 2006 into the Massachusetts Alzheimer's Disease Research Center (MADRC) patient registry.

Setting-Community-based.

Participants-771 persons aged 65 years or older with a clinical diagnosis of AD.

Measurements-Hospitalization, delirium, death, and institutionalization were identified through administrative databases. Cognitive decline was defined as a decrease of 4 or more points on the Blessed Information-Memory-Concentration test score. Multivariate analysis was used to calculate adjusted relative risks (RRs).

\footnotetext{
(C) 2012 American College of Physicians

Requests for Single Reprints: Tamara G. Fong, MD, PhD, Aging Brain Center, Institute for Aging Research, Hebrew SeniorLife, 1200 Centre Street, Boston, MA 02131; tfong @ bidmc.harvard.edu.

Current author addresses and author contributions are available at www.annals.org.

Current Author Addresses: Drs. Fong, Jones, Gross, Schmitt, and Inouye and Mr. Tommet and Mr. Habtemariam: Aging Brain Center, Institute for Aging Research, Hebrew SeniorLife, 1200 Centre Street, Boston, MA 02131.

Dr. Marcantonio: Department of Medicine, Beth Israel Deaconess Medical Center, 330 Brookline Avenue, Boston, MA 02215.

Dr. Yap: Massachusetts General Hospital, Warren Building, Suite 844, 55 Fruit Street, Boston, MA 02114.
}

Potential Conflicts of Interest: Disclosures can be viewed at www.acponline.org/authors/icmje/ConflictOfInterestForms.do? msNum=M11-2645.

Reproducible Research Statement: Study protocol and data set: Not available. Statistical code: Available from Dr. Fong (tfong@bidmc.harvard.edu).

Author Contributions: Conception and design: R.N. Jones, E.R. Marcantonio, S.K. Inouye.

Analysis and interpretation of the data: T.G. Fong, R.N. Jones, D. Tommet, A.L. Gross, D. Habtemariam, E. Schmitt, S.K. Inouye. Drafting of the article: T.G. Fong, R.N. Jones, S.K. Inouye.

Critical revision of the article for important intellectual content: T.G. Fong, R.N. Jones, E.R. Marcantonio, D. Tommet, A.L. Gross, D. Habtemariam, E. Schmitt, L. Yap, S.K. Inouye.

Final approval of the article: T.G. Fong, R.N. Jones, E.R. Marcantonio, A.L. Gross, D. Habtemariam, E. Schmitt, S.K. Inouye.

Provision of study materials or patients: L. Yap.

Statistical expertise: R.N. Jones, D. Tommet, A.L. Gross, S.K. Inouye.

Obtaining of funding: S.K. Inouye.

Administrative, technical, or logistic support: D. Habtemariam, E. Schmitt, L. Yap, S.K. Inouye.

Collection and assembly of data: D. Tommet, A.L. Gross, L. Yap. 
Results-Of 771 participants with AD, 367 (48\%) were hospitalized and 194 (25\%) developed delirium. Hospitalized patients who did not have delirium had an increased risk for death (adjusted RR, 4.7 [95\% CI, 1.9 to 11.6]) and institutionalization (adjusted RR, 6.9 [CI, 4.0 to 11.7]). With delirium, risk for death (adjusted RR, 5.4 [CI, 2.3 to 12.5]) and institutionalization (adjusted RR, 9.3 [CI, 5.5 to 15.7]) increased further. With hospitalization and delirium, the adjusted RR for cognitive decline for patients with $\mathrm{AD}$ was 1.6 (CI, 1.2 to 2.3). Among hospitalized patients with $\mathrm{AD}, 21 \%$ of the incidences of cognitive decline, $15 \%$ of institutionalization, and $6 \%$ of deaths were associated with delirium.

Limitations-Cognitive outcome was missing in 291 patients. Sensitivity analysis was performed to test the effect of missing data, and a composite outcome was used to decrease the effect of missing data.

Conclusion-Approximately 1 in 8 hospitalized patients with AD who develop delirium will have at least 1 adverse outcome, including death, institutionalization, or cognitive decline, associated with delirium. Delirium prevention may represent an important strategy for reducing adverse outcomes in this population.

Primary Funding Source-National Institute on Aging and the MADRC.

Hospitalization can be a major life-changing event with potentially catastrophic consequences for patients with Alzheimer disease (AD). Complications, including delirium, loss of independence, institutionalization, and death, are common outcomes $(1,2)$ that contribute substantially to the economic burden of $\mathrm{AD}$. The risk for hospitalization is increased 3-fold for patients with AD (3-6). Each year, 20\% to 40\% of patients with AD are hospitalized for an average of 3.7 days per person-year.

During an average of 3 years in a cohort of community-dwelling patients with AD, we found that up to two thirds had at least 1 hospitalization, nearly one half experienced 2 or more hospitalizations (7), and an episode of delirium could increase the rate of cognitive decline (8). Although these factors distinguish patients with $\mathrm{AD}$ as having high risk for hospitalization and demonstrate the substantial effect of delirium on cognitive decline, the relative contributions of hospitalization and delirium to poor outcomes have not been previously examined. Our study expands on previous work documenting the effect of delirium on hospital outcomes (9) in patients with AD.

In this study, outcomes associated with hospitalization and delirium were examined by using a clinical epidemiologic cohort created by merging a clinical sample of patients followed in the Massachusetts Alzheimer's Disease Research Center (MADRC) with data from the Medicare Provider Analysis and Review (MEDPAR) database, medical records, the Social Security Death Index database, and the National Death Index (NDI). Our specific aims were to identify 1-year outcomes, including death, institutionalization, cognitive decline, and an overall composite of these outcomes, associated with hospitalization and delirium in a community-dwelling cohort of patients with $\mathrm{AD}$; examine the adjusted risks for the study outcomes for the hospitalized group with and without delirium; and determine the attributable risks for hospitalization and delirium for each of the study outcomes. We hypothesized that hospitalization and delirium, independent of relevant covariates, would contribute incrementally to negative outcomes. Confirming that hospitalization and delirium play important roles in adverse outcomes may ultimately influence care and management of patients with $\mathrm{AD}$. 


\section{Methods}

\section{Setting and Participants}

Participants were drawn from a prospective cohort of consecutive patients enrolled between 1 January 1991 and 30 June 2006 into the MADRC patient registry. Established in 1984 as a National Institutes of Health Specialized Research Center for evaluation of persons with memory loss, the MADRC has evaluated more than 5600 patients at the Massachusetts General Hospital (MGH), a 900-bed Harvard-affiliated teaching hospital. The current study was nested within the MADRC cohort as part of a longitudinal study of hospitalization in AD described previously (7).

Patients aged 65 years or older with a diagnosis of probable or possible AD according to guidelines from the National Institute of Neurological and Communicative Diseases and Stroke and the Alzheimer's Disease and Related Disorders Association (10) who were not enrolled in a Medicare HMO, had at least 3 MADRC visits during the study interval, and gave informed consent were considered for the study $(n=825)$. Participants hospitalized after 1 January $2006(n=23)$ were ineligible, because 1-year follow-up would not be complete within the study time frame (through 31 December 2006).

Hospitalizations were identified by using the MEDPAR database, and corresponding medical charts were reviewed. The hospitalized group included participants hospitalized within 18 months of an MADRC visit. Participants without medical records for hospitalization were excluded $(n=5)$. The nonhospitalized group included participants without any hospitalizations identified by MEDPAR for up to 36 months after an MADRC visit. Participants hospitalized between 18 and 36 months after the MADRC visit were excluded from the study $(n=26)$ because they could not be validly assigned to either group. Thus, the final sample included 771 participants.

Written informed consent for use of MADRC and clinical data for research was obtained jointly from participants and family members, next of kin, a health care proxy, or a courtappointed guardian according to procedures approved by the MGH institutional review board. The institutional review board at MGH and Hebrew SeniorLife approved the current study using merged MADRC, Medicare, and NDI data. Local institutional review board approval at more than 40 additional Massachusetts hospitals was obtained for review of medical charts.

\section{Data Collection}

The baseline MADRC visit, defined as the visit before hospitalization, included demographic characteristics; medical history; neurologic examination; and cognitive testing, including the Information-Memory-Concentration (IMC) subtest of the Blessed Dementia Scale test (11). Dementia severity was rated across all time points by using the MGH Dementia Severity Rating (DSR) scale, an MADRC-created scale that rates general levels of functional dependence (range, 0 to 5 , with 5 indicating profound impairment) and correlates highly with the widely used Clinical Dementia Rating scale (Spearman correlation coefficient, 0.87) (8). Family history of AD, symptom duration, rapid onset of symptoms, and a fluctuating or stepwise disease course were also noted.

Follow-up MADRC assessments occurred approximately every 6 months and followed a standardized protocol, including updated history, physical examination, and cognitive testing. The MEDPAR and Denominator files, which include demographic and Medicare enrollment information, were obtained for 1991 through 2006 from the Centers for Medicare $\&$ Medicaid Services. The Denominator file identified MADRC patients included in the Medicare database by matching on numerous key variables, including Social Security 
number, date of birth, and sex. Information on all hospitalizations and Medicare-eligible nursing home stays, along with dates, length of stay, location, admitting diagnoses, and additional medical diagnoses, was obtained from MEDPAR.

For each index hospitalization, which was identified by Medicare or MADRC records, trained clinical chart abstractors (2 physicians and 2 nurses) reviewed the medical record. Delirium was identified by chart review (12) on the basis of recognition of key terms or presence of mental status or behavioral changes by using a method validated against the Confusion Assessment Method (13). The Confusion Assessment Method has a sensitivity of $74 \%$ (95\% CI, $65 \%$ to $81 \%$ ), specificity of $83 \%$ (CI, $80 \%$ to $86 \%$ ), and positive likelihood ratio of 4.4 (CI, 3.6 to 5.3); however, in moderate to severe cases of delirium (representing the clinically relevant cases), sensitivity was nearly $90 \%$ (12).

Information on admitting diagnoses, comorbid conditions, and length of hospital stay was abstracted from medical records. Diagnoses from MEDPAR, chart reviews, and MADRC data were used to calculate the Charlson-Deyo comorbidity score $(14,15)$.

Procedures were enacted to balance the observation period for the nonhospitalized group with that of the hospitalized group. For each patient in the nonhospitalized group, a visit within that patient's interval of MADRC participation was selected at random to represent that nonhospitalized patient's index MADRC visit. The average length of time between the index MADRC visit and index hospitalization in the hospitalized group was then used to define a "pseudohospitalization date" for the nonhospitalized group (16). Multiple nonhospitalized participants were available per hospitalized patient, and the selection of the index visit was chosen to balance follow-up times between groups.

\section{Outcomes}

Adverse outcomes included institutionalization, cognitive decline, or death within 1 year of index hospitalization. Information on nursing home placement was taken from chart review or MADRC records. Deaths were confirmed by using a multistep process. First, exact matches with the NDI database for 1991 through 2006 as the reference standard were identified. If no exact match was found, then the best match with the NDI plus additional supporting data (that is, MADRC or Social Security Death Index data) were used. Finally, 33 cases underwent clinical adjudication by an expert panel of physicians (1 neurologist and 3 geriatricians). Date of death was taken from the death certificate (preferred reference standard) or other source (medical record or Medicare or Social Security database). On the basis of previous work, cognitive decline was defined as a loss of 4 or more points from baseline on the Blessed IMC test score (17-19).

A composite of any adverse outcome within 1 year, including death, institutionalization, or cognitive decline, was used for several reasons. Outcomes are not mutually exclusive and some are hierarchical. For example, if a patient died, institutionalization or cognitive decline could not be additional outcomes, although patients who were institutionalized could have death or cognitive decline as outcomes. The use of composite outcomes can increase efficiency, decrease the effect of missing data, and resolve arbitrary choices among multiple important outcomes (20).

\section{Statistical Analysis}

To compare baseline characteristics, 1-way analysis of variance was used for continuous variables and the chi-square test was used for categorical variables. Outcome rates across the study groups specified a priori (hospitalized with delirium, hospitalized without delirium, and nonhospitalized) were compared by using the chi-square test for trend. Poisson regression was performed to calculate unadjusted and adjusted relative risks (RRs). Relevant 
covariates included age, race, education, family history of AD, Blessed IMC test score, DSR scale score, duration of symptoms, speed of initial symptom onset, intensive care unit admission indicating severe illness, and Charlson-Deyo comorbidity score.

The population attributable risk (PAR), measuring the potential proportion by which the incidence of the outcomes could be reduced if hospitalization or delirium were eliminated, was calculated as the product of a function of the RR of the outcome among hospitalized patients with delirium ([RR - 1]/RR) and the prevalence of delirium among those hospitalized. The risk for each adverse outcome (attributable to delirium) was calculated as the inverse of the attributable risk. An analysis stratified by baseline cognitive function was also conducted to examine the effect of delirium within strata of cognitive functioning.

Death and institutionalization outcomes were ascertained in full, without missing data. However, cognitive decline could be confirmed only for participants who returned for repeated cognitive testing. Sources of missing Blessed IMC test scores included missed MADRC follow-up within 7 months of the index hospitalization $(n=443)$, incomplete cognitive data $(n=321)$, death $(n=20)$, institutionalization $(n=90)$, or loss to follow-up ( $n$ =372). The small amount of missing data among control variables (Table 1) was managed with multiple imputation methods by using 20 data sets, and prediction models of missing values were estimated by using all available observed data and the method of chained equations (21). To test the effect of missing data, sensitivity analyses were performed.

\section{Role of the Funding Source}

The MADRC and the National Institute on Aging funded the study. The MADRC was involved in collection of data, specifically patient demographic characteristics, medical history, neurologic examination, and cognitive testing. The funding sources were not involved in the study design, analysis, or interpretation of data or in the preparation or submission of the manuscript for publication.

\section{Results}

Table 1 shows baseline characteristics of the overall cohort $(n=771)$, patients hospitalized with delirium $(n=194$ [25\%]), patients hospitalized without delirium $(n=173$ [22\%]), and nonhospitalized patients $(n=404[52 \%])$. The mean age was 77.2 years, more than $50 \%$ were women (57\%), and most patients were white (95\%). The mean Blessed IMC test score was 12.5 , and DSR scale scores averaged 2.4 out of 5.0, with a mean duration of symptoms of 3.1 years. Mean Charlson-Deyo comorbidity index scores of 0.8 were low. These demographic characteristics indicate that the cohort was relatively high-functioning, with few comorbid conditions and only mild stages of AD. The median length of follow-up was 2 years (interquartile range, 0.94 to 3.41 years), and the median time between MADRC visits was 0.54 years (interquartile range, 0.50 to 0.67 years). Rehospitalization occurred in hospitalized groups both with $(n=130[67 \%])$ and without $(n=95[55 \%])$ delirium during the study period (difference in proportions, $13 \%$ [CI, 3\% to 23\%]).

Hospitalized patients had more comorbid conditions and were older and slightly less educated than the nonhospitalized group. The hospitalized group with delirium had the most cognitive impairment at baseline and was the most impaired according to the DSR scale. These baseline differences were carefully adjusted in all subsequent analyses.

Figure 1 shows the time sequence for the development of study outcomes. Tables 2 and 3 demonstrate the overall outcomes 1 year after hospitalization. The composite outcome showed that at least 1 adverse outcome occurred in 32\% of the nonhospitalized group, 55\% of the hospitalized group without delirium, and $79 \%$ of the hospitalized group with delirium, 
highlighting the association of hospitalization and the incremental effect of delirium with negative outcomes in this population of patients with $\mathrm{AD}$.

The most common individual outcome in the hospitalized group with delirium was institutionalization, which occurred in $43 \%$, compared with just $4 \%$ in the nonhospitalized group. Death occurred in $2 \%$ of the nonhospitalized group, $9 \%$ of the hospitalized group without delirium, and $15 \%$ of the hospitalized group with delirium. Cognitive decline was observed in all groups, as expected given the progressive nature of $\mathrm{AD}$.

Table 4 shows the RRs for adverse outcomes, adjusted for race, education, family history of $\mathrm{AD}$, baseline Blessed IMC test score, DSR scale score, duration of symptoms, speed of initial onset of symptoms, intensive care unit admission, and Charlson-Deyo comorbidity score. For any adverse outcome, the unadjusted RR was 1.8 (CI, 1.4 to 2.2) for hospitalized patients without delirium and 2.5 (CI, 2.0 to 3.0) for those with delirium. The unadjusted RR for death among hospitalized participants was 5.3 (CI, 2.2 to 12.8) in those without delirium but increased to 8.9 (CI, 4.0 to 20.0) in those with delirium.

For institutionalization, the unadjusted RR for hospitalization was 7.3 (CI, 4.3 to 12.5), but it was higher in hospitalized patients with delirium (RR, 10.8 [CI, 6.5 to 18.0]). Cognitive decline had an unadjusted RR of 0.9 (CI, 0.6 to 1.3 ) with hospitalization and no delirium and 1.6 (CI, 1.2 to 2.2 ) with hospitalization with delirium. After adjustment was made for confounding factors, hospitalization alone was associated with a greatly increased adjusted risk for death (4.7 [CI, 1.9 to 11.6]) and for institutionalization (6.9 [CI, 4.0 to 11.7]); if delirium also occurred, these risks increased incrementally to 5.4 (CI, 2.3 to 12.5) for hospitalization alone and 9.3 (CI, 5.5 to 15.7) for institutionalization.

In addition to adjustment for baseline cognitive scores and variables of dementia severity, stratified analyses were conducted to examine the association of delirium within strata of cognitive functioning. A Blessed IMC test score of 15 or greater (22) was used to classify patients as having major cognitive impairment, whereas those with less cognitive impairment had Blessed IMC test scores less than 15. The increased risks associated with delirium persisted within strata (data not shown).

To assess the association of delirium among hospitalized patients with adverse outcomes, both absolute attributable risks and PARs were considered. The outcome with the greatest absolute risk among hospitalized patients with delirium was institutionalization (83 out of 194 , or $43 \%$ ), followed by cognitive decline (38 out of $194-101$, or $41 \%$ ) (Table 2) and death (30 out of 194, or 15\%) (Table 2). These risks were higher than those of hospitalized patients who did not develop delirium (Table 3).

Table 4 summarizes the PARs for the composite and individual outcomes attributable to delirium among hospitalized patients. The attributable risk estimates can be interpreted as the expected decline in occurrence of the negative outcome if delirium were eliminated, excepting the potential for residual confounding or other sufficient causes of these outcomes (23). The number needed to be exposed to hospitalization and delirium that was associated with 1 fewer occurrence of a negative outcome within 1 year (1/PAR) is also reported.

For hospitalized patients with AD, approximately 1 in 16 deaths, 1 in 7 institutionalizations, and 1 in 5 cases of cognitive decline within 1 year can be attributed to delirium. For the composite outcome, approximately 1 in 8 patients with $\mathrm{AD}$ who develop delirium will have a negative outcome that is attributable to the delirium, assuming no residual confounding or alternative causal mechanisms for these outcomes. 
Further analyses were conducted to examine the distribution of outcomes and missing cognitive data for patients who were institutionalized $(n=66)$ or died $(n=20)$ or had both $(n$ $=24)$ or neither $(n=181)$ of the outcomes. As a result of missing cognitive data, the sample size for each outcome differs, as shown in Figure 2. A sensitivity analysis was performed for assumptions made on missing data in the cognitive decline outcome and combined outcome.

We repeated all models, assuming first that all participants missing cognitive follow-up had cognitive decline and then that all participants had no cognitive decline. This method enabled us to examine the extremes of the effect of missing data on our results. The patterns of the results were unchanged, and the significance levels were essentially the same across all analyses. Appendix Tables 1 and 2 (available at www.annals.org) show detailed results of this sensitivity analysis.

\section{Discussion}

This study shows that, in patients with $\mathrm{AD}$, hospitalization is associated with increased risks for adverse outcomes. The risk for poor outcomes is greater among patients who develop delirium, even after controlling for cogent confounders. Among hospitalized patients, a substantial proportion of risk for adverse outcomes could be attributed to deliriumspecifically, $6.2 \%$ of deaths, $15.2 \%$ of institutionalization, $20.6 \%$ of cognitive decline, and $12.4 \%$ of adverse outcomes overall.

Given our previous work $(7,8)$ documenting the frequency of hospitalization among patients with $\mathrm{AD}$, the increased risk for cognitive decline, and acceleration of cognitive decline after delirium, these results highlight an important and potentially high-yield target for future prevention strategies. Previous studies examining poor outcomes associated with hospitalization $(24,25)$ have been limited by the lack of measurement of delirium as a potential contributing factor. Our study builds on previous work to examine the association of both hospitalization and delirium on subsequent outcomes in patients with AD.

This study represents a unique, large-scale epidemiologic examination of the outcomes of hospitalization in a community-dwelling population of persons with AD. Although hospitalization may negatively affect patients with other types of dementia, we restricted our analyses to $\mathrm{AD}$ to focus on the most common form of dementia with a well-described clinical course. The MADRC data provide high-quality information in a well-characterized clinical cohort. The merging of Medicare, Social Security Death Index, and NDI data makes this clinical cohort useful as a real-world epidemiologic cohort, a major strength of this study. Use of real-world clinical populations has become increasingly important for better understanding of outcomes of care $(26,27)$.

The presence of delirium was assessed by using a validated method. Finally, ascertainment of death by using the NDI data and nursing home placement was complete and rigorous and verified by multiple sources of information to maximize the quality of the outcome data.

Although causality cannot be established from an observational epidemiologic investigation, this study used many approaches to maximize causal inference (28). These approaches include describing the magnitude of statistical associations, maximizing the validity of associations (that is, controlling for baseline differences in the cohorts and multiple sensitivity analyses testing different assumptions), verifying temporal precedence (that is, confirming that delirium occurs before the outcomes), and establishing biological plausibility (that is, demonstrating that delirium is well-recognized to lead to adverse outcomes). 
Our estimates of attributable risk should be interpreted with caution and may not reflect causal effects of delirium on institutionalization, cognitive decline, or death. Because of the potential for residual confounding, differential measurement error, or informative censoring, our results should be interpreted with caution $(23,29)$. However, we carefully addressed these limitations by adjusting for known risk factors and conducting sensitivity analyses to evaluate the robustness of our findings.

Several important caveats are worth mentioning. Given the nonrandomized nature of this observational study, baseline cognitive function differed among study groups, with the group of hospitalized patients with delirium being most impaired. However, effects were carefully controlled through covariate adjustment and further examined in stratified analyses and suggest that delirium independently contributed to the poor outcomes observed.

Representation of ethnic minorities in the MADRC cohort is low (5\%) and all data are obtained from 1 site (the MADRC), which limit the generalizability of the findings. Nevertheless, our sample is directly comparable to that of the National Alzheimer's Coordinating Center cohort $(n=74169)$ in terms of demographic characteristics and dementia severity, except that $18 \%$ of their sample is composed of minorities.

A notable limitation of our study is missing data in this real-world clinical cohort. Thus, we used a composite measure and merged multiple databases to create a real-world cohort, which is an effective way to minimize missing data and bias (30). Further, the effect of missing data was carefully assessed, with sensitivity analyses assigning extreme values (best case or worst case) to missing data; this assessment did not affect results. Thus, we are confident about the internal validity of our findings and conclusions.

Analyses are limited to those outcomes present in our data. For example, data on functional status were available only on a limited number of patients during follow-up; thus, this factor was not further examined as a study outcome. Likewise, the occurrence of delirium in the nonhospitalized group could not be assessed. However, a large retrospective study on delirium superimposed on dementia in a community-dwelling, managed care population found that the incidence of delirium was $13 \%$ (1), and delirium in a general community setting is very low (between $1 \%$ to $2 \%)(31,32)$. Thus, we anticipate that the number of nonhospitalized persons with delirium is relatively small. Finally, because of limitations of the Medicare data, our analysis could not separate short-term nursing home stays from longterm stays.

Hospitalization is common in patients with $\mathrm{AD}$, and this study demonstrates the important and incremental associations of hospitalization and delirium with 1-year outcomes in patients with AD. Future work is greatly needed to determine whether prevention of delirium and hospitalization is possible in the high-risk population of persons with $\mathrm{AD}$, and, if possible, whether this will substantially reduce the adverse outcomes of progressive cognitive impairment, institutionalization, and death observed in this study. Further investigation is greatly needed to determine whether prevention of hospitalization and delirium can decrease the attributable risk for death, institutionalization, and cognitive impairment in the vulnerable and increasing population of persons with AD.

\section{Acknowledgments}

The authors thank Drs. John Growdon and Brad Hyman for access to the MADRC patient registry data and for providing the initial pilot grant supporting this work. They also thank Drs. Virginia Casey and Gregory Acampora for assistance with chart reviews. This work is dedicated to the memory of Joshua Bryan Inouye Helfand.

Grant Support: Funded in part by grant IIRG-08-88737 to Dr. Inouye from the Alzheimer's Association and grants P50AG005134 to Drs. Inouye and Yap, P01AG031720 to Dr. Inouye, and K24AG035075 to Dr. 
Marcantonio from the National Institute on Aging, as well as the Aging Brain Center, Institute for Aging Research, Hebrew SeniorLife.

\section{References}

1. Fick DM, Kolanowski AM, Waller JL, Inouye SK. Delirium superimposed on dementia in a community-dwelling managed care population: a 3-year retrospective study of occurrence, costs, and utilization. J Gerontol A Biol Sci Med Sci. 2005; 60:748-753. [PMID: 15983178]. [PubMed: 15983178]

2. Pedone C, Ercolani S, Catani M, Maggio D, Ruggiero C, Quartesan R, et al. GIFA Study Group. Elderly patients with cognitive impairment have a high risk for functional decline during hospitalization: the GIFA Study. J Gerontol A Biol Sci Med Sci. 2005; 60:1576-1580. [PMID: 16424291]. [PubMed: 16424291]

3. Fillenbaum G, Heyman A, Peterson B, Pieper C, Weiman AL. Frequency and duration of hospitalization of patients with AD based on Medicare data: CERAD XX. Neurology. 2000; 54:740-743. [PMID: 10680815]. [PubMed: 10680815]

4. Maslow, K. How many people with dementia are hospitalized?. In: Silverstein, N.; Maslow, K., editors. Improving Hospital Care for Persons with Dementia. New York: Springer Pub; 2006. p. 740-743.

5. Weiler PG, Lubben JE, Chi I. Cognitive impairment and hospital use. Am J Public Health. 1991; 81:1153-1157. [PMID: 1951826]. [PubMed: 1951826]

6. Zhu CW, Scarmeas N, Torgan R, Albert M, Brandt J, Blacker D, et al. Longitudinal study of effects of patient characteristics on direct costs in Alzheimer disease. Neurology. 2006; 67:998-1005. [PMID: 16914696]. [PubMed: 16914696]

7. Rudolph JL, Zanin NM, Jones RN, Marcantonio ER, Fong TG, Yang FM, et al. Hospitalization in community-dwelling persons with Alzheimer's disease: frequency and causes. J Am Geriatr Soc. 2010; 58:1542-1548. [PMID: 20553338]. [PubMed: 20553338]

8. Fong TG, Jones RN, Shi P, Marcantonio ER, Yap L, Rudolph JL, et al. Delirium accelerates cognitive decline in Alzheimer disease. Neurology. 2009; 72:1570-1575. [PMID: 19414723]. [PubMed: 19414723]

9. Witlox J, Eurelings LS, de Jonghe JF, Kalisvaart KJ, Eikelenboom P, van Gool WA. Delirium in elderly patients and the risk of postdischarge mortality, institutionalization, and dementia: a metaanalysis. JAMA. 2010; 304:443-451. [PMID: 20664045]. [PubMed: 20664045]

10. McKhann G, Drachman D, Folstein M, Katzman R, Price D, Stadlan EM. Clinical diagnosis of Alzheimer's disease: report of the NINCDS-ADRDA Work Group under the auspices of Department of Health and Human Services Task Force on Alzheimer's Disease. Neurology. 1984; 34:939-944. [PMID: 6610841]. [PubMed: 6610841]

11. Blessed G, Tomlinson BE, Roth M. The association between quantitative measures of dementia and of senile change in the cerebral grey matter of elderly subjects. Br J Psychiatry. 1968; 114:797-811. [PMID: 5662937]. [PubMed: 5662937]

12. Inouye SK, Leo-Summers L, Zhang Y, Bogardus ST Jr, Leslie DL, Agostini JV. A chart-based method for identification of delirium: validation compared with interviewer ratings using the confusion assessment method. J Am Geriatr Soc. 2005; 53:312-318. [PMID: 15673358]. [PubMed: 15673358]

13. Inouye SK, van Dyck CH, Alessi CA, Balkin S, Siegal AP, Horwitz RI. Clarifying confusion: the confusion assessment method. A new method for detection of delirium. Ann Intern Med. 1990; 113:941-948. [PMID: 2240918]. [PubMed: 2240918]

14. Charlson ME, Pompei P, Ales KL, MacKenzie CR. A new method of classifying prognostic comorbidity in longitudinal studies: development and validation. J Chronic Dis. 1987; 40:373383. [PMID: 3558716]. [PubMed: 3558716]

15. Deyo RA, Cherkin DC, Ciol MA. Adapting a clinical comorbidity index for use with ICD-9-CM administrative databases. J Clin Epidemiol. 1992; 45:613-619. [PMID: 1607900]. [PubMed: 1607900] 
16. Avidan MS, Searleman AC, Storandt M, Barnett K, Vannucci A, Saager L, et al. Long-term cognitive decline in older subjects was not attributable to non-cardiac surgery or major illness. Anesthesiology. 2009; 111:964-970. [PMID: 19786858]. [PubMed: 19786858]

17. Katzman R, Brown T, Thal LJ, Fuld PA, Aronson M, Butters N, et al. Comparison of rate of annual change of mental status score in four independent studies of patients with Alzheimer's disease. Ann Neurol. 1988; 24:384-389. [PMID: 3228273]. [PubMed: 3228273]

18. Locascio JJ, Growdon JH, Corkin S. Cognitive test performance in detecting, staging, and tracking Alzheimer's disease. Arch Neurol. 1995; 52:1087-1099. [PMID: 7487561]. [PubMed: 7487561]

19. Salmon DP, Thal LJ, Butters N, Heindel WC. Longitudinal evaluation of dementia of the Alzheimer type: a comparison of 3 standardized mental status examinations. Neurology. 1990; 40:1225-1230. [PMID: 2381530]. [PubMed: 2381530]

20. Cordoba G, Schwartz L, Woloshin S, Bae H, Gøtzsche PC. Definition, reporting, and interpretation of composite outcomes in clinical trials: systematic review. BMJ. 2010; 341:c3920. [PMID: 20719825]. [PubMed: 20719825]

21. Royston P. Multiple imputation of missing values: update. Stata J. 2005; 5:118-201.

22. Stern Y, Mayeux R, Sano M, Hauser WA, Bush T. Predictors of disease course in patients with probable Alzheimer's disease. Neurology. 1987; 37:1649-1653. [PMID: 3658173]. [PubMed: 3658173]

23. Rothman, KJ.; Greenland, S. Modern Epidemiology. Philadelphia: Lippincott Williams \& Wilkins; 1998.

24. Ehlenbach WJ, Hough CL, Crane PK, Haneuse SJ, Carson SS, Curtis JR, et al. Association between acute care and critical illness hospitalization and cognitive function in older adults. JAMA. 2010; 303:763-770. [PMID: 20179286]. [PubMed: 20179286]

25. Gill TM, Allore HG, Gahbauer EA, Murphy TE. Change in disability after hospitalization or restricted activity in older persons. JAMA. 2010; 304:1919-1928. [PMID: 21045098]. [PubMed: 21045098]

26. Epstein RS, Sherwood LM. From outcomes research to disease management: a guide for the perplexed. Ann Intern Med. 1996; 124:832-837. [PMID: 8610953]. [PubMed: 8610953]

27. Powell AE, Davies HT, Thomson RG. Using routine comparative data to assess the quality of health care: understanding and avoiding common pitfalls. Qual Saf Health Care. 2003; 12:122128. [PMID: 12679509]. [PubMed: 12679509]

28. Rothman KJ, Greenland S. Causation and causal inference in epidemiology. Am J Public Health. 2005; 95(Suppl 1):S144-S150. [PMID: 16030331]. [PubMed: 16030331]

29. Greenland S, Robins JM. Conceptual problems in the definition and interpretation of attributable fractions. Am J Epidemiol. 1988; 128:1185-1197. [PMID: 3057878]. [PubMed: 3057878]

30. Nguyen LL, Barshes NR. Analysis of large databases in vascular surgery. J Vasc Surg. 2010; 52:768-774. [PMID: 20598475]. [PubMed: 20598475]

31. Folstein MF, Bassett SS, Romanoski AJ, Nestadt G. The epidemiology of delirium in the community: the Eastern Baltimore Mental Health Survey. Int Psychogeriatr. 1991; 3:169-176. [PMID: 1811771]. [PubMed: 1811771]

32. Rahkonen T, Eloniemi-Sulkava U, Paanila S, Halonen P, Sivenius J, Sulkava R. Systematic intervention for supporting community care of elderly people after a delirium episode. Int Psychogeriatr. 2001; 13:37-49. [PMID: 11352333]. [PubMed: 11352333] 


\section{Appendix Table 1}

Adjusted and Unadjusted Relative Risks for Cognitive Decline and Any Adverse Outcome*

\begin{tabular}{lll}
\hline Variable & \multicolumn{2}{c}{ Relative Risk $(95 \%$ CI) } \\
\cline { 2 - 3 } & Hospitalized & Hospitalized \\
& $\begin{array}{l}\text { Patients } \\
\text { Without } \\
\text { Delirium }\end{array}$ & $\begin{array}{l}\text { Patients } \\
\text { With } \\
\text { Delirium }\end{array}$ \\
& & (
\end{tabular}

Assuming That All Persons Missing Data on Cognitive Decline Did Not Have Decline

\begin{tabular}{lll}
\hline Cognitive decline $(\boldsymbol{n}=\mathbf{7 7 1})$ & & \\
\hline Unadjusted & $0.8(0.5-1.1)$ & $1.1(0.7-1.5)$ \\
\hline $\begin{array}{l}\text { Adjusted }{ }^{*} \\
\text { Any adverse outcome }(\boldsymbol{n}=\mathbf{7 7 1})\end{array}$ & $0.8(0.5-1.3)$ & $1.2(0.8-1.7)$ \\
\hline Unadjusted & $2.0(1.5-2.4)$ & $2.8(2.2-3.4)$ \\
\hline Adjusted ${ }^{*}$ & $1.9(1.5-2.4)$ & $2.5(2.0-3.2)$
\end{tabular}

Assuming That All Persons Missing Data on Cognitive Decline Did Have Decline

Cognitive decline $(n=771)$

\begin{tabular}{lcc}
\hline Unadjusted & $1.1(0.9-1.2)$ & $1.5(1.3-1.7)$ \\
\hline Adjusted $^{*}$ & $1.1(0.9-1.3)$ & $1.4(1.2-1.6)$
\end{tabular}

Any adverse outcome $(n=771)$

\begin{tabular}{lcc}
\hline Unadjusted & $1.3(1.1-1.5)$ & $1.6(1.4-1.8)$ \\
\hline Adjusted $f$ & $1.3(1.1-1.5)$ & $1.5(1.4-1.7)$ \\
\hline
\end{tabular}

Numbers of persons with missing data are as follows: race, 7; education, 13; family history of dementia, 1; Dementia Severity Rating scale score, 33; duration of symptoms, 11; and speed of initial symptom onset, 42.

Compared with nonhospitalized patients (referent).

${ }^{7}$ Adjusted for age, sex, race, education, family history of dementia, Dementia Severity Rating scale score, duration of symptoms, speed of initial onset, Charlson-Deyo comorbidity score, and intensive care unit admission.

\section{Appendix Table 2}

Attributable Risk for Cognitive Decline and Any Adverse Outcome Due to Delirium Among Hospitalized Patients With Alzheimer Disease

\begin{tabular}{llllll}
\hline Variable & $\begin{array}{l}\text { Assuming That All } \\
\text { Persons Missing Data } \\
\text { on Cognitive Decline } \\
\text { Did Not Have } \\
\text { Decline }\end{array}$ & $\begin{array}{l}\text { Assuming That All } \\
\text { Persons Missing Data } \\
\text { on Cognitive Decline } \\
\text { Did Have Decline }\end{array}$ \\
\cline { 2 - 3 } \cline { 5 - 6 } & $\begin{array}{l}\text { Cognitive } \\
\text { Decline }\end{array}$ & $\begin{array}{l}\text { Any } \\
\text { Adverse } \\
\text { Outcome }\end{array}$ & $\begin{array}{l}\text { Cognitive } \\
\text { Decline }\end{array}$ & $\begin{array}{l}\text { Any } \\
\text { Adverse } \\
\text { Outcome }\end{array}$ \\
\hline Attributable risk, $\%$ & 17.1 & 13.9 & 10.6 & 8.8 \\
\hline
\end{tabular}




\begin{tabular}{llllll}
\hline Variable & $\begin{array}{l}\text { Assuming That All } \\
\text { Persons Missing Data } \\
\text { on Cognitive Decline } \\
\text { Did Not Have } \\
\text { Decline }\end{array}$ & $\begin{array}{l}\text { Assuming That All } \\
\text { Persons Missing Data } \\
\text { on Cognitive Decline } \\
\text { Did Have Decline }\end{array}$ \\
\cline { 2 - 4 } & $\begin{array}{l}\text { Cognitive } \\
\text { Decline }\end{array}$ & $\begin{array}{l}\text { Any } \\
\text { Adverse } \\
\text { Outcome }\end{array}$ & $\begin{array}{l}\text { Cognitive } \\
\text { Decline }\end{array}$ & $\begin{array}{l}\text { Any } \\
\text { Adverse } \\
\text { Outcome }\end{array}$ \\
\hline Risk for adverse outcome (attributable to delirium) & 1 in 6 & 1 in 7 & 1 in 9 & 1 in 11 \\
\hline The attributable risk is the product of a function of the relative risk (RR) of the outcome among those hospitalized with \\
delirium ([RR - 1]/RR) and the prevalence of delirium among those hospitalized.
\end{tabular}




\section{Context}

Hospitalization of patients with Alzheimer disease (AD) is frequent and commonly leads to serious complications. The relative role of hospitalization itself and of delirium developing during hospitalization in the occurrence of complications is important to elucidate.

\section{Contribution}

In a large prospective cohort of patients with $\mathrm{AD}$, hospitalization itself was associated with a substantial increase in the risk for death and institutionalization. The occurrence of delirium during hospitalization further increased these risks. Delirium was also associated with an increased risk for further cognitive decline.

\section{Caution}

Causality cannot be inferred from this observational study.

\section{Implication}

In patients with $\mathrm{AD}$, interventions to prevent hospitalization and hospital-associated delirium may be appropriate.

- The Editors 


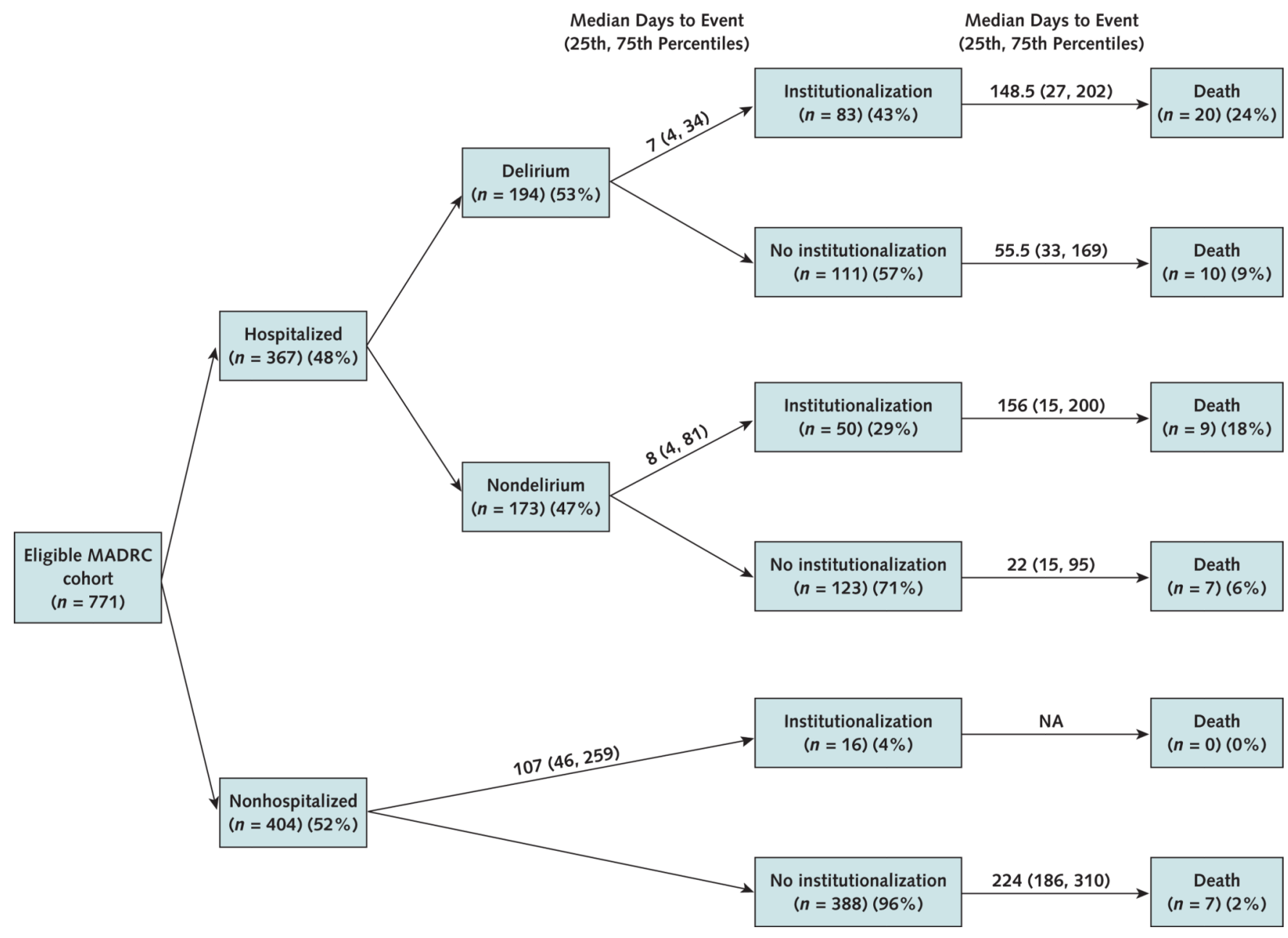

Figure 1. Temporal course of outcomes used in this study

Institutionalization and death are events that happen within $1 \mathrm{y}$ of hospitalization. Median days to event refers to the median length of time from one outcome to the next. MADRC = Massachusetts Alzheimer's Disease Research Center; NA = not available. 


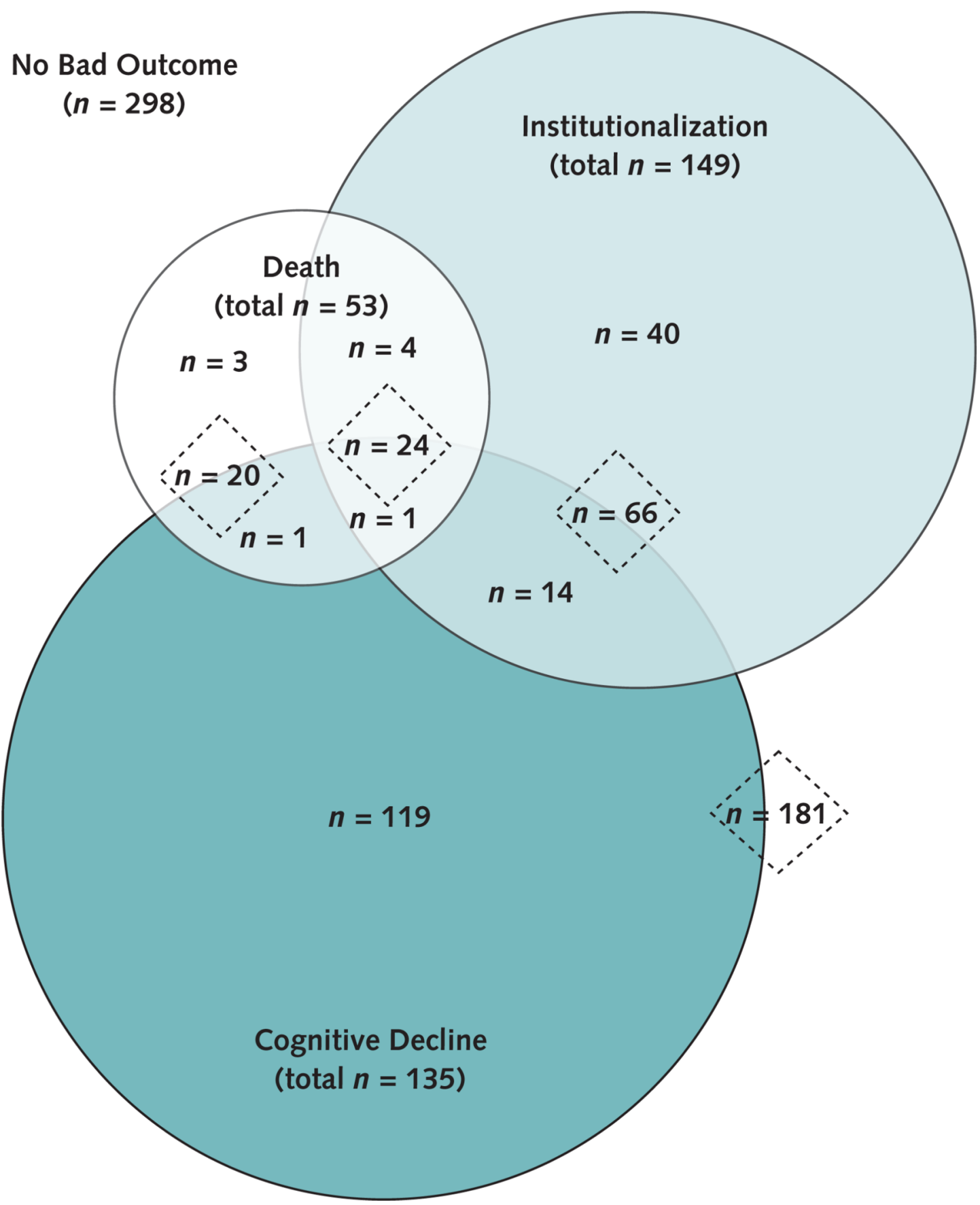

Figure 2. Overlap of outcomes of hospitalization and delirium combined to form the composite outcome

The sizes of the circles and overlaps are proportional to the total number of patients with those outcomes. The dotted diamonds indicate missing data for the outcome of cognitive decline, because classification of these participants inside (or outside) of the cognitive decline circle could not be made. Some cases where the outcome of cognitive decline was not known with certainty included persons who were known to have died $(n=20)$, who had been institutionalized and then died $(n=24)$, or who were institutionalized $(n=66)$. An additional 181 participants were known to be alive, but their outcome of cognitive decline 
was not known. The total number indicated for each outcome includes those who had missing data. 
Table 1

Characteristics of the Study Sample*

\begin{tabular}{|c|c|c|c|c|}
\hline Variable & $\begin{array}{l}\text { Total Participants } \\
(n=771)\end{array}$ & $\begin{array}{l}\text { Hospitalized Patients } \\
\text { With Delirium }(n= \\
\text { 194) }\end{array}$ & $\begin{array}{l}\text { Hospitalized Patients } \\
\text { Without Delirium ( } n \\
=173 \text { ) }\end{array}$ & $\begin{array}{l}\text { Nonhospitalized } \\
\text { Patients }(n=404)\end{array}$ \\
\hline \multicolumn{5}{|l|}{ Demographic characteristics } \\
\hline Mean age (SD), $y$ & $77.2(6.3)$ & $78.7(6.2)$ & $78.8(5.8)$ & $75.9(6.2)$ \\
\hline Men, $n(\%)$ & $330(43)$ & $102(53)$ & $63(36)$ & $165(41)$ \\
\hline Nonwhite, $n(\%)$ & $37(5)$ & $12(6)$ & $7(4)$ & $18(5)$ \\
\hline Mean education (SD), $y$ & $14.0(3.4)$ & $13.4(3.7)$ & $13.9(3.4)$ & $14.2(3.3)$ \\
\hline \multicolumn{5}{|l|}{ Dementia-related factors } \\
\hline Family history of $\mathrm{AD}, n(\%)$ & $57(7)$ & $15(8)$ & $16(9)$ & $26(7)$ \\
\hline Mean Blessed IMC test score (SD) ${ }^{\dagger}$ & $12.5(7.1)$ & $14.6(7.4)$ & $10.8(6.8)$ & $12.2(6.9)$ \\
\hline Mean DSR scale score (SD) $)^{t}$ & $2.4(0.9)$ & $2.7(0.9)$ & $2.3(1.0)$ & $2.4(0.9)$ \\
\hline Mean duration of symptoms (SD), $y$ & $3.1(2.1)$ & $2.8(2.0)$ & $3.1(2.3)$ & $3.2(2.1)$ \\
\hline Rapid speed of initial symptom onset, $n(\%)$ & $46(6)$ & $11(6)$ & $9(6)$ & $26(7)$ \\
\hline Fluctuating or stepwise disease course, $n(\%)$ & $24(3)$ & $5(3)$ & $1(1)$ & $18(5)$ \\
\hline
\end{tabular}

Illness-related factors, $n(\%)$

Charlson-Deyo comorbidity score $\mathcal{E}$

\begin{tabular}{|c|c|c|c|c|}
\hline 0 & $419(54)$ & $86(44)$ & $82(47)$ & $251(62)$ \\
\hline 1 & $196(25)$ & $61(31)$ & $51(30)$ & $84(21)$ \\
\hline$\geq 2$ & $156(20)$ & $47(24)$ & $40(23)$ & $69(17)$ \\
\hline Intensive care unit admission & $25(3)$ & $15(8)$ & $10(6)$ & $0(0)$ \\
\hline \multicolumn{5}{|l|}{ Admission diagnosis, $n(\%)^{/ /}$} \\
\hline Syncope, fall, trauma & $99(27.0)$ & $51(26.3)$ & $48(27.7)$ & NA \\
\hline Ischemic heart disease & $58(15.8)$ & $27(13.9)$ & $31(17.9)$ & NA \\
\hline Gastrointestinal disease & $34(9.3)$ & $16(8.2)$ & $18(10.4)$ & NA \\
\hline Pneumonia & $25(6.8)$ & $19(9.8)$ & $6(3.5)$ & NA \\
\hline Musculoskeletal symptoms & $17(4.6)$ & $10(5.2)$ & $7(4.0)$ & NA \\
\hline Delirium, mental status change & $15(4.1)$ & $11(5.7)$ & $4(2.3)$ & NA \\
\hline Cerebrovascular disease & $15(4.1)$ & $10(5.2)$ & $5(2.9)$ & NA \\
\hline
\end{tabular}




\begin{tabular}{lllll}
\hline Variable & $\begin{array}{l}\text { Total Participants } \\
(\boldsymbol{n}=\mathbf{7 7 1})\end{array}$ & $\begin{array}{l}\text { Hospitalized Patients } \\
\text { With Delirium }(\boldsymbol{n}= \\
\mathbf{1 9 4})\end{array}$ & $\begin{array}{l}\text { Hospitalized Patients } \\
\text { Without Delirium }(\boldsymbol{n} \\
=\mathbf{1 7 3})\end{array}$ & $\begin{array}{l}\text { Nonhospitalized } \\
\text { Patients }(\boldsymbol{n}=\mathbf{4 0 4})\end{array}$ \\
CNS or neurologic symptoms & $9(2.5)$ & $6(3.1)$ & $3(1.7)$ & NA \\
\hline Urinary tract infection & $8(2.2)$ & $4(2.1)$ & $4(2.3)$ & NA \\
\hline Cancer & $8(2.2)$ & $2(1.0)$ & $6(3.5)$ & NA \\
\hline Other Il & $79(21.5)$ & $38(19.6)$ & $41(23.7)$ & NA \\
\hline
\end{tabular}

$\mathrm{AD}=$ Alzheimer disease CNS = central nervous system; DSR = Dementia Severity Rating; IMC = Information-Memory-Concentration; NA = not available.

\footnotetext{
*
}

* Demographic characteristics with significant differences $(P<0.05)$ between groups include age, sex, education level, Blessed IMC test score, SR scale score, intensive care unit admission, and Charlson-Deyo comorbidity score. These variables were all controlled for in subsequent analyses. Missing data consist of race $(n=6)$, education $(n=12)$, family history of dementia $(n=1)$, Blessed IMC test score $(n=77)$, DSR scale score $(n=$ $34)$, duration of symptoms $(n=10)$, speed of initial onset $(n=12)$, and course $(n=14)$.

${ }^{\dagger}$ Blessed IMC test score ranges from 0 to 37 points, with 37 indicating the worst score.

tDSR scale score ranges from 0 to 5 , with 5 indicating the worst score.

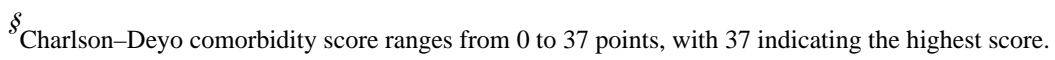

"Determined from principal admitting diagnosis for corresponding Medicare claim record; missing for 29 hospitalizations.

II Other admission diagnoses include chronic lung disease, congestive heart failure, fever, other infections, dehydration, acute or chronic renal failure, peripheral vascular disease, psychiatric illness, and diabetes mellitus. 


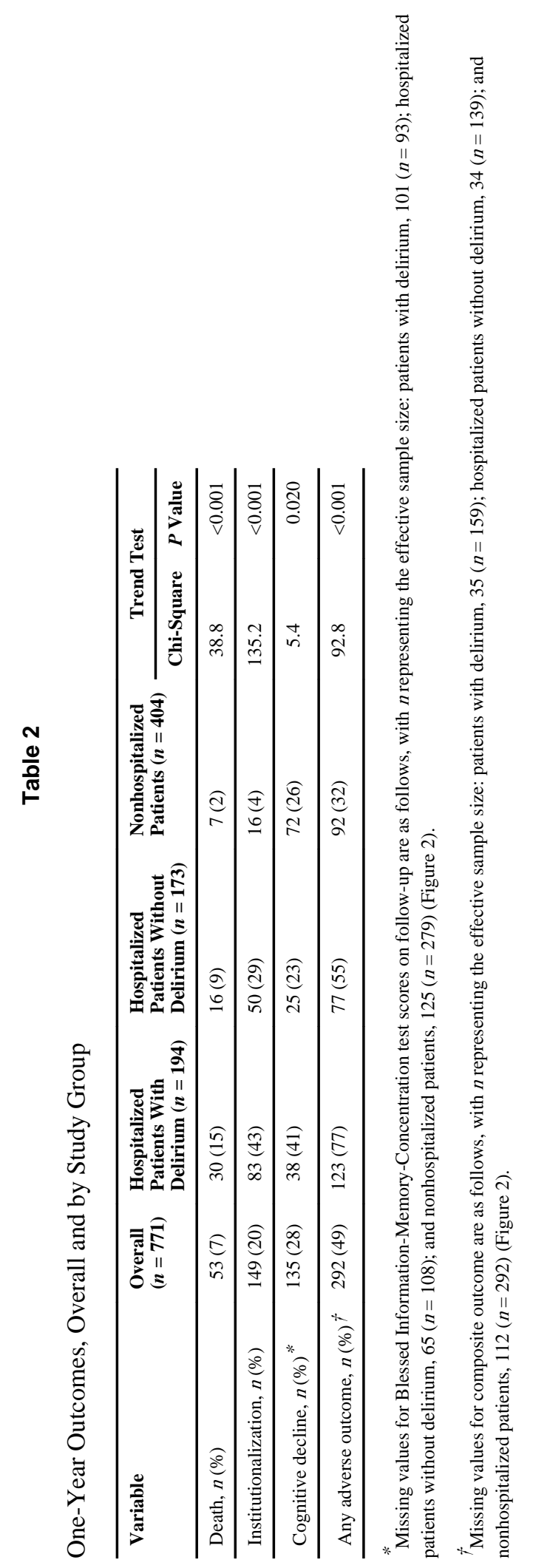

Ann Intern Med. Author manuscript; available in PMC 2013 June 19. 


\section{Table 3}

Adjusted and Unadjusted Relative Risks for Death, Institutionalization, Cognitive Decline, and Any Adverse Outcome*

\begin{tabular}{lll}
\hline Variable & \multicolumn{2}{c}{ Relative Risk $(95 \%$ CI $)$} \\
\cline { 2 - 3 } & Hospitalized & Hospitalized \\
Patients & Patients With \\
Without & Delirium \\
Delirium & Del $^{\dagger}$
\end{tabular}

Death $(n=771)$

\begin{tabular}{lll}
\hline Unadjusted & $5.3(2.2-12.8)$ & $8.9(4.0-20.0)$ \\
\hline Adjusted ${ }^{\dagger}$ & $4.7(1.9-11.6)$ & $5.4(2.3-12.5)$
\end{tabular}

Institutionalization $(n=771)$

\begin{tabular}{llr}
\hline Unadjusted & $7.3(4.3-12.5)$ & $10.8(6.5-18.0)$ \\
\hline Adjusted ${ }^{*}$ & $6.9(4.0-11.7)$ & $9.3(5.5-15.7)$
\end{tabular}

Cognitive decline $(n=480)$

\begin{tabular}{lcc}
\hline Unadjusted & $0.9(0.6-1.3)$ & $1.6(1.2-2.2)$ \\
\hline Adjusted $^{*}$ & $0.9(0.6-1.4)$ & $1.6(1.2-2.3)$
\end{tabular}

Any adverse outcome $(n=590)$

\begin{tabular}{ccc}
\hline Unadjusted & $1.8(1.4-2.2)$ & $2.5(2.0-3.0)$ \\
\hline Adjusted $\%$ & $1.7(1.4-2.2)$ & $2.2(1.8-2.7)$ \\
\hline
\end{tabular}

* Numbers of persons with missing data are as follows: race, 7; education, 13; family history of dementia, 1; Dementia Severity Rating scale score, 33 ; duration of symptoms, 11; and speed of initial symptom onset, 42.

${ }^{\dagger}$ Compared with nonhospitalized patients (referent).

${ }^{7}$ Adjusted for age, sex, race, education, family history of dementia, Dementia Severity Rating scale score, duration of symptoms, speed of initial onset, Charlson-Deyo comorbidity score, and intensive care unit admission. 
Table 4

Attributable Risk for Death, Institutionalization, Cognitive Decline, and Any Adverse Outcome due to Delirium Among Hospitalized Patients With Alzheimer Disease

\begin{tabular}{lllll}
\hline Variable & Death & Institutionalization & $\begin{array}{l}\text { Cognitive } \\
\text { Decline }\end{array}$ & $\begin{array}{l}\text { Any } \\
\text { Adverse } \\
\text { Outcome }\end{array}$ \\
\hline Attributable risk, $\%^{*}$ & 6.2 & 15.2 & 20.6 & 12.4 \\
\hline Risk for adverse outcome (attributable to delirium) & 1 in 16 & 1 in 7 & 1 in 5 & 1 in 8 \\
\hline
\end{tabular}

* The attributable risk is the product of a function of the relative risk (RR) of the outcome among those hospitalized with delirium ([RR - 1]/RR) and the prevalence of delirium among those hospitalized. 